Veritas Et Scientia

Vol. 7, N² 2, 905-915

Julio - Diciembre del 2018.

ISSN Edición Online: 2617-0639

https://doi.org/10.47796/ves.v7i2.67

\title{
FRAGMENTACIÓN DEL JUICIO ORAL Y LA AFECTACIÓN DE LA CALIDAD DEL JUZGAMIENTO EN LA CORTE SUPERIOR DE JUSTICIA DE TACNA-2016.
}

\author{
FRAGMENTATION OF THE ORAL JUDGMENT AND THE AFFECTATION OF THE QUALITY OF THE \\ JUDGMENT IN THE SUPERIOR COURT OF JUSTICE OF TACNA-2016.
}

Pedro David Franco Apaza ${ }^{1}$

Presentado: 09/06/2018

Aceptado: 09/07/2018

Publicado online:27/12/2018

\section{RESUMEN}

El presente trabajo de investigación trata sobre la fragmentación del juicio oral y la afectación de la calidad del juzgamiento en el Juzgado Penal Colegiado de la Corte Superior de Justicia de Tacna-2016, la que se llevó a cabo con el propósito de determinar si la fragmentación del juicio oral afecta a la calidad del juzgamiento, en el Juzgado Penal Colegiado de la Corte Superior de Justicia de Tacna-2016. Para ello se estableció la siguiente hipótesis: Probablemente la fragmentación de la audiencia del juicio oral, afecte considerablemente la calidad del juzgamiento en el Juzgado Penal Colegiado de la Corte Superior de Justicia de Tacna-2016. El trabajo corresponde a una investigación de tipo básica, nivel explicativo; y, diseño no experimental. Para tal propósito se consideró la información obtenida a través del cuestionario aplicado a 170 profesionales del derecho en materia penal, la cédula de entrevista a los jueces de juzgamiento (04) y la ficha de análisis (83 sentencias); como instrumentos de medición de las variables: independiente (fragmentación del juicio oral) y variable dependiente (calidad del juzgamiento). Los datos obtenidos se tabularon y analizaron mediante tablas y figuras. Una vez finalizada la fase de análisis e interpretación de los resultados se precisó que: Probablemente la fragmentación de la audiencia del Juicio Oral, afecte considerablemente la calidad del juzgamiento en el Juzgado Penal Colegiado de la Corte Superior de Justicia de Tacna-2016.

Palabras clave: Audiencia, fragmentación, juicio oral

\footnotetext{
${ }^{1}$ Doctor en Derecho Penal y Política Criminal
} 


\begin{abstract}
The present research work deals with the fragmentation of the oral trial and the effect of the quality of the trial in the Criminal Court of the Superior Court of Justice of Tacna-2016, which was carried out with the purpose of determining if the fragmentation of the oral trial affects the quality of the trial in the Criminal Court of the Superior Court of Justice of Tacna-2016. For this, the following hypothesis was established. Probably the fragmentation of the hearing of the oral trial, considerably affect the quality of the trial in the Criminal Court of the Superior Court of Justice of Tacna-2016. The work corresponds to a basic type of investigation, an explanatory level; and, nonexperimental design. For this purpose, the information obtained through the questionnaire applied to 170 legal professionals in criminal matters, the interview card for trial judges (04) and the analysis card (83 judgments) were considered; as instruments for measuring the variables: independent (fragmentation of oral judgment) and dependent variable (quality of judgment). The data obtained were tabulated and analyzed by tables and figures. Once the phase of analysis and interpretation of the results was completed, it was specified that: Probably the fragmentation of the hearing of the Oral Trial, considerably affects the quality of the trial in the Criminal Court of the Superior Court of Justice of Tacna-2016.
\end{abstract}

Keywords: Audience, fragmentation, oral trial.

\title{
INTRODUCCIÓN
}

El presente trabajo trata sobre la fragmentación del juicio oral y la afectación de la calidad del juzgamiento en la Corte Superior de Justicia de Tacna-2016. La promulgación del Nuevo Código Procesal Penal mediante el Decreto Legislativo 957, ha estado motivada por múltiples causas que desnaturalizaba el proceso penal, tornándolo lento; así el juicio oral se presentaba notoriamente discontinuo e inacabable, apreciación que el Nuevo Código Procesal Penal pretende erradicar, proponiendo un nuevo proceso penal caracterizado por diferentes etapas y a cargo de diferentes operadores.

"El proceso penal se divide en tres grandes etapas: una de investigación, una etapa intermedia para debatir la viabilidad del juicio y finalmente la del juicio esta última es naturalmente la más importante y, dentro de ella, a su vez, la del debate oral". (San Martín, 2005, p.245). Por ello el debate debe desarrollarse en forma oral, pública y continua, con plena posibilidad de contradicción, en igualdad de condiciones, para lo cual se requiere la presencia permanente de todos los integrantes del tribunal. El juzgamiento o el juicio oral, conforme prescribe el Nuevo Código Procesal Penal peruano, es la etapa principal del proceso penal; y tiene estrecha vinculación con la justicia, que se pretende alcanzar. El juicio oral una vez abierto es continuo y no puede suspenderse en su trámite, (arts. 356.2 y 360.1 Nuevo Código Procesal Penal). Las sesiones son continuas e ininterrumpidas; $y$, entre ellas, no podrán realizarse otros juicios, salvo aquellos permitidos por ley (art. 360.5 NCPP).

La concentración del juicio oral se debe a la efectividad de la realidad e inmediación, por cuanto los jueces que intervienen, fuera de las notas que puedan tomar, retienen todo en la

Veritas et Scientia Vol. 7 (2) Julio - diciembre 2018. 906 
mente, lo mismo que las partes, por lo que al final de la actividad probatoria cuenten con la información inmediata, fresca y conjunta que les permita emitir sus conclusiones de manera congruente (alegatos finales y sentencia). La suspensión de la audiencia es el detenimiento de la actividad procesal, la cual no podrá exceder de ocho días hábiles (art. 360.3 NCPP). Superado el impedimento, el juicio continúa al día siguiente del cese. Si dura más de ese plazo produce la interrupción que obliga a la reiniciación del debate. La regla establecida por el art. 360.3, último extremo, del NCPP, que dispone que, por la interrupción del acto oral, esa parte del debate queda sin efecto y debe señalarse una nueva fecha para su realización, asimismo debe ser matizada en función a la ulterior posibilidad de un error en la valoración probatoria. La continuidad en el juicio también comprende a la sentencia.

El principio que capta nuestro interés, es el de continuidad; principio que va íntimamente ligado con el principio de concentración. El principio de continuidad, sobre todos en sus excepciones, tiene un vínculo directo con el actuar ético de los sujetos procesales, en especial con los litigantes, abogados públicos y privados, Ministerio Público, y Judicatura, quienes tendrán a su cargo la responsabilidad ético-profesional, de permitir que este principio se lleve a cabo cumpliendo con sus fines $y$, no utilizar las excepciones legales. Ponemos en evidencia la deficiente práctica desarrollada en la Audiencia de Juzgamiento en Tacna, al fraccionar las audiencias de juicio oral en innumerables sesiones, quebrantando el principio de la unidad de la audiencia e imposibilitando a que el juzgador tenga una mejor apreciación en las pruebas que se actúan en su presencia. El fin de esta investigación, es evidenciar las deficientes prácticas arraigadas a la fecha, como manifestaciones del modelo pasado, representado en la suspensión de las audiencias de juicio oral por diferentes motivos relacionados a defectos en la dirección de audiencias de juzgamiento, complejidad del caso por el número de pruebas admitidas en la etapa intermedia, sin precisar la utilidad, la diversidad de criterios o inadecuada interpretación de las normas que rigen la actividad probatoria, etc., problema que también se evidencia en la labor que realiza el representante del Ministerio Público y defensa técnica, que se ven obligados a repasar cada sesión anterior, recapitular y reestructurar su teoría del caso. Entiéndase la concentración y continuidad del juicio oral tiene como objetivo la obtención de información de manera inmediata y con ello permitir, formular sus teorías de manera ajustadas a lo actuado en audiencia. Fernández, I. (2010). señala que el juicio oral es la fase más importante del proceso penal acusatorio porque sirve especialmente para comprobar la certeza última de la acusación, su verdadera dimensión. López, C. (2012) publica que la prolongación excesiva de la audiencia de juicio oral por sucesivas suspensiones de la audiencia, configura causal de nulidad por violación de la garantía fundamental al Debido Proceso. Murillo, I. (2010) señala que los juicios orales tendrán las mismas etapas de un juicio escrito, solo que en un menor número de audiencias y de forma oral, esto se hace con el objetivo de reducir tiempo y dinero. Torres, A. (2013) afirma que los juicios orales son una medida necesaria en estos tiempos ya que la sociedad está siendo rebasada tanto en el ámbito jurídico. Mejía, G. (2001) refiere que incluso Venezuela ya entró a formar parte de los países que aplican una justicia que garantiza la efectiva realización del principio "audiatur et altera pars", con un fallo que será dictado con base en los actos orales y no basado en actas escritas. Osorio, O, \& Sierra, L. (2015). describe en cuanto al juicio oral en los países donde se ha implementado este sistema, ha traído beneficios, los cuales se reflejan en la seguridad de los ciudadanos frente al sistema de justicia del respectivo país. Ramírez, J. (2011) señala que en lo que respecta a Costa Rica, la Legislación Procesal Penal vigente evidenció la división del proceso en tres etapas y donde las cuales se fundamentan en un principio de oralidad, estas tres etapas constan de una etapa de investigación, seguido de una etapa intermedia para finalizar con una etapa de juicio oral y público. Cajas, A. (2009). Recomienda que es necesario en el juicio se depuren los rezagos inquisitivos que aún contiene. En el Perú, Villavicencio, F.

Veritas et Scientia Vol. 7 (2) Julio - diciembre 2018. 907 
(2010). señala que, en el nuevo modelo procesal penal, existe una vinculación directa entre la tutela de los derechos fundamentales - como el derecho de defensa y el derecho al plazo razonable- y el principio de celeridad procesal. Ccasa, G. (2016) en Arequipa, refiere que queda comprobado que el nuevo proceso penal en el Perú exige la optimización de los derechos constitucionales para ello en cada fase la regla debe ser protección de los derechos del imputado y su restricción como excepción cuando el caso concreto lo amerite. Está comprobado que la cesura de juicio oral apareció como una propuesta para poder optimizar aún más los derechos del imputado en la fase de juicio oral siguiendo la política de optimización de los derechos fundamentales del denominado "sistema procesal acusatorio". El tratadista Alsina afirma que "los autores convienen que la justicia debe ser rápida, económica y segura". (Alsina,1956). Por su parte, Ricardo Levene sostiene que el mejor régimen procesal es aquel que se funda en el procedimiento oral, público y continuo o concentrado, ante tribunales colegiados de única instancia, con un sistema probatorio basado en la sana crítica y que corresponda a las garantías constitucionales y a las normas pertinentes de la legislación de fondo. (Levene, 1993, p.105). Asimismo, "no se puede proceder a juicio oral sin que exista previa acusación fiscal". (Frank, 1986). Alberto Binder (1993) refiere que la oralidad es un instrumento, un mecanismo previsto para garantizar ciertos principios básicos del juicio penal. En especial, para preservar el principio de inmediación, la publicidad del juicio y la personalización de la función judicial.

El Nuevo Código Procesal Penal Peruano, señala que la audiencia se realiza oralmente, pero se documenta en acta, asimismo, la audiencia puede registrarse mediante un medio técnico, la que contendrá una síntesis de lo actuado en la audiencia; los Jueces, el Fiscal y la defensa de las partes pueden hacer constar las observaciones que estimen convenientes (inc. 1, art. $361^{\circ}$ ).

La fragmentación y dispersión del juicio oral, en sesiones discontinuas, es un agudo problema actual; su abordaje crítico es urgente, pero en perspectiva de proponer alternativas de solución. "La discusión del problema será razonable sólo, en tanto y en cuanto, proponga alternativas de solución a la fragmentación de la audiencia". (Maier,2004, p.75). "El acto oral es una actividad procesal penal compleja y unitaria. Los periodos procesales que comprende, por consiguiente, no pueden alterarse". (San Martín,2015).

\section{Objetivos}

a) Conocer cómo afectan los diferentes tipos de procesos en juicio oral al principio de concentración en el Juzgado Penal Colegiado de la Corte Superior de Justicia de Tacna-2016.

b) Identificar cómo afecta la suspensión del juicio oral al principio de continuidad y cómo afecta la instalación simultánea de audiencias al principio de inmediación en el Juzgado Penal Colegiado de la Corte Superior de Justicia de Tacna-2016.

\section{METODOLOGÍA}

Tipo de investigación Básica, de nivel explicativo en el campo jurídico-social, con enfoque mixto. Se aplicó el método lógico inductivo de diseño no experimental, de corte transversal, y comprende los procesos judiciales del Juzgado Penal Colegiado de Tacna, siendo el tiempo social de la investigación el período 2016. La población de estudio estará comprendida por 106 procesos judiciales del Juzgado Penal Colegiado de Tacna y 303 profesionales del derecho (abogados, fiscales y jueces). Mediante muestreo aleatorio estratificado se trabajó finalmente con 83 sentencias y 170 profesionales del derecho penal: 4 jueces, 9 fiscales y 157 abogados penalistas. Para la recolección de datos se recurrió a la aplicación de los instrumentos de medición de la ficha de análisis documental, cuestionario y cédula de entrevista.

Veritas et Scientia Vol. 7 (2) Julio - diciembre 2018. 908 


\section{RESULTADOS}

En el 53\% de los juicios orales se realizan de 11 a 15 sesiones por expediente; en el $25 \%$ de 6 a 10 sesiones; en el $13 \%$ de 16 a 20 sesiones por expediente; en el 7\% de 1 a 5 sesiones por expediente; $y$, en el $1 \%$ de los casos de 21 a 25 sesiones por expediente. Lo que permite concluir que la mayoría de juicios orales se realizan en 11 a 15 sesiones por expediente, lo que afecta el principio de concentración. Asimismo, el 100\% de los juicios orales se realizan de 1 a 5 actos procesales por expediente judicial. Se puedo observar que en su mayoría se realizan de 1 a 5 actos procesales por sesión, en ningún caso se realiza el total de actos procesales del juicio oral. Lo que permite concluir que los juicios orales no se realizan de acuerdo a lo que establece el principio de concentración (juicio iniciado, juicio terminado).

El 54\% de los juicios orales duran de 3 a 5 meses; en el 41\% de0 a 2 meses; $y$, en el 5\% hasta 6 meses. En el $84 \%$ de los juicios orales se ha producido inconcurrencia de los testigos o peritos; y en menores porcentajes se ha producido la inconcurrencia de los jueces, fiscales, defensores e imputados. En la mayoría la inconcurrencia se da por la inasistencia de los órganos de prueba (testigos o peritos). En el 55\% de los casos, las causas de suspensión han sido determinadas por la inconcurrencia de los órganos de prueba (causal no prevista en el Código Penal); en el $16 \%$ de los casos por cruce de audiencias, el $11 \%$ por pedido injustificado de las partes. Quedando que en el $73 \%$ de los juicios orales han sido discontinuos; y en el $27 \%$ de los casos ocurre lo contrario. Según el Número de sesiones por juicio oral, en el 53\% de los procesos judiciales se realizan entre 11 a 15 sesiones; el 25\% de 6 a 10 sesiones; el $13 \%$ de 16 a 20 sesiones; el 7\% de las audiencias se realizan de 1 a 5 sesiones; y el $1 \%$ de las audiencias entre 21 a 25 sesiones. La audiencia del juicio oral se realiza con fragmentación afectando el principio de continuidad del juzgamiento.

El 98\% de los procesos judiciales en el Juzgado Penal Colegiado de la Corte Superior de Tacna son de tipo común; y, sólo el $2 \%$ son de tipo complejo y según tipo de delito existe un mayor porcentaje de delitos de robo agravado (32\%); el $28 \%$ a violación sexual al menor; $y$, el $10 \%$ de delitos a tráfico ilícito de drogas (tabla 01).

Tabla 1

Tipo de delitos

\begin{tabular}{lcc}
\hline Tipo de delitos & $\mathbf{f}$ & \% \\
\hline a) Robo agravado & 27 & 32 \\
b) TID & 8 & 10 \\
c) Violación sexual al menor & 23 & 28 \\
d) Contrabando & 2 & 2 \\
e) Resistencia a la autoridad & 3 & 4 \\
f) Defraudación de rentas de aduanas & 2 & 2 \\
g) Hurto de ganado & 1 & 1 \\
h) Actos contra el pudor & 7 & 8 \\
i) Trata de personas & 1 & 1 \\
j) Peculado doloso agravado & 1 & 1 \\
k) Homicidio & 2 & 2 \\
l) Cohecho pasivo & 1 & 1 \\
m) Tráfico de mercaderías prohibidas & 5 & 6 \\
Total & 83 & 100 \\
\hline
\end{tabular}

Veritas et Scientia Vol. 7 (2) Julio - diciembre 2018. 909 


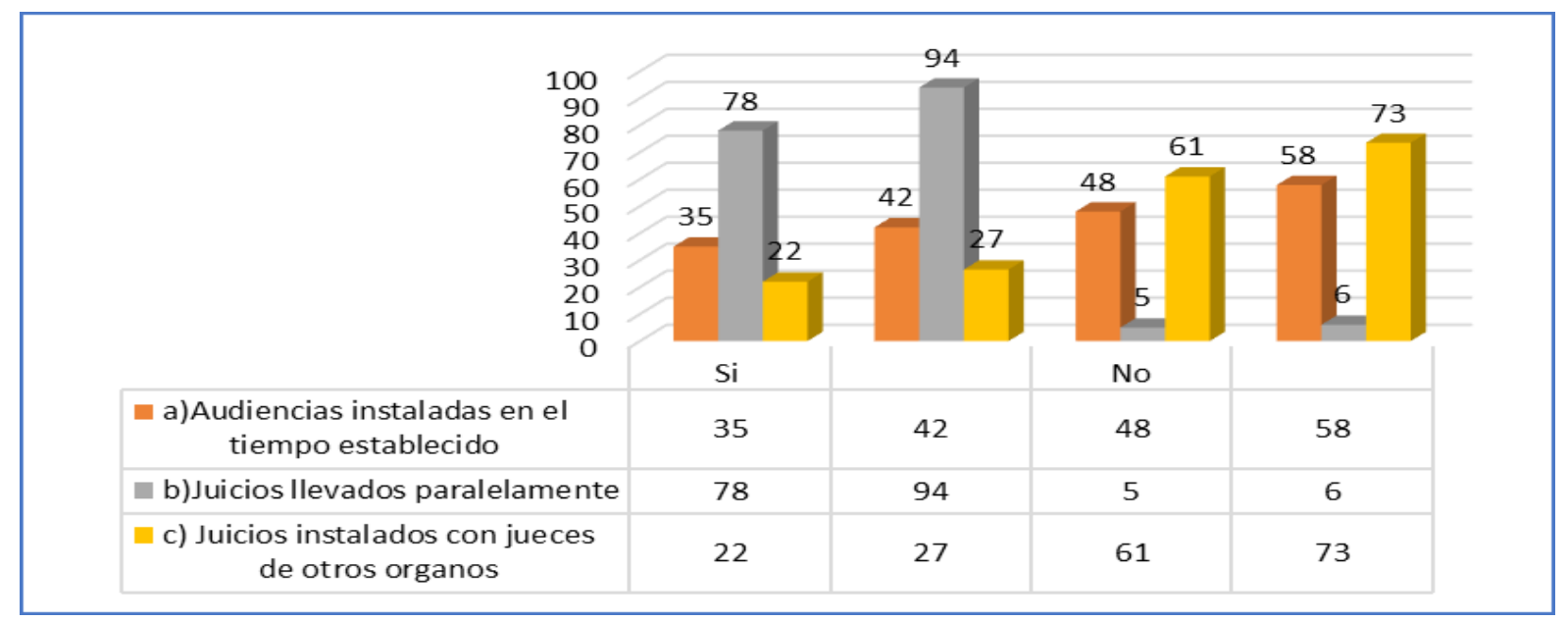

\section{Figura 1}

Instalación simultánea de audiencias

En figura 1 se observa que en el $58 \%$ de los juicios orales no se han instalado las audiencias en el tiempo establecido; en el $94 \%$ de los juicios orales, los juicios son llevados paralelamente; $y$, en el $27 \%$ de los juicios orales, los juicios han sido instalados con jueces de otros órganos. Lo que permite concluir que en la mayoría de los juicios orales en el juzgado penal colegiados el desarrollo de las audiencias se ve afectados por la instalación simultánea de audiencias, lo que afecta el principio de continuidad del juzgamiento en la Corte Superior de Justicia de Tacna. Asimismo, en el $52 \%$ de los juicios orales no se cumple la presencia ininterrumpida de los sujetos procesales. En el $27 \%$ el tiempo aproximado por sesión es de 16 a 20 minutos; en la mayoría de los juicios orales las sesiones son breves al no actuarse mayores diligencias. En el $51 \%$ no se produce la interrelación directa entre los jueces y la prueba.

\section{Resultados del cuestionario aplicado a los profesionales del derecho}

\begin{tabular}{|c|c|c|}
\hline Abogados & Jueces & Fiscales \\
\hline $\begin{array}{l}92 \% \text { señalaron que las } \\
\text { Audiencias de Juicio Oral no se } \\
\text { llevan a cabo de acuerdo al } \\
\text { artículo } 360^{\circ} \text { del Código } \\
\text { Procesal Penal }\end{array}$ & $\begin{array}{l}75 \% \text { señalaron que las } \\
\text { Audiencias de Juicio Oral no se } \\
\text { llevan a cabo de acuerdo al } \\
\text { artículo } 360^{\circ} \text { del Código } \\
\text { Procesal Penal }\end{array}$ & $\begin{array}{l}78 \% \text { señalaron que las } \\
\text { Audiencias de Juicio Oral no se } \\
\text { llevan a cabo de acuerdo al } \\
\text { artículo } 360^{\circ} \text { del Código Procesal } \\
\text { Penal }\end{array}$ \\
\hline $\begin{array}{l}\text { 49\% señalaron que las causas de } \\
\text { la discontinuidad son: el } \\
\text { incumplimiento de las causales } \\
\text { de suspensión; el } 29 \% \text { señaló } \\
\text { que fue la instalación } \\
\text { simultánea de audiencias. }\end{array}$ & $\begin{array}{l}\text { El } 100 \% \text { señalaron que las } \\
\text { causas de la discontinuidad son } \\
\text { por el incumplimiento de las } \\
\text { causales de suspensión }\end{array}$ & $\begin{array}{l}\text { El } 100 \% \text { señalaron que las } \\
\text { causas de la discontinuidad son } \\
\text { por el incumplimiento de las } \\
\text { causales de suspensión }\end{array}$ \\
\hline $\begin{array}{l}92 \% \text { señalaron que en el } \\
\text { Juzgado Penal Colegiado se } \\
\text { estaría produciendo una alta } \\
\text { fragmentación de los juicios } \\
\text { orales }\end{array}$ & $\begin{array}{l}\text { El } 100 \% \text { encuestados señalaron } \\
\text { que en el Juzgado Penal } \\
\text { Colegiado se } \\
\text { produciendo estaría } \\
\text { fragmentación de los juicios } \\
\text { orales. }\end{array}$ & $\begin{array}{l}\text { El } 89 \% \text { sostuvieron que en el } \\
\text { Juzgado Penal Colegiado se } \\
\text { estaría produciendo una alta } \\
\text { fragmentación de los juicios } \\
\text { orales }\end{array}$ \\
\hline $\begin{array}{l}\text { El } 89 \% \text { refiere se estaría } \\
\text { afectando el principio de } \\
\text { concentración }\end{array}$ & $\begin{array}{l}\text { El } 75 \% \text { refiere se estaría } \\
\text { afectando el principio de } \\
\text { concentración }\end{array}$ & $\begin{array}{l}\text { El } 78 \% \text { refiere se estaría } \\
\text { afectando el principio de } \\
\text { concentración }\end{array}$ \\
\hline El $96 \%$ refiere & El 75\% refiere se estaría & El $89 \%$ refiere se estaría \\
\hline
\end{tabular}

Veritas et Scientia Vol. 7 (2) Julio - diciembre 2018. 910 


\begin{tabular}{|c|c|c|}
\hline $\begin{array}{l}\text { afectando el principio de } \\
\text { continuidad }\end{array}$ & $\begin{array}{l}\text { afectando el principio de } \\
\text { continuidad }\end{array}$ & $\begin{array}{l}\text { afectando el principio de } \\
\text { continuidad }\end{array}$ \\
\hline $\begin{array}{l}\text { El } 94 \% \text {, no se suspenden sólo } \\
\text { por a) por razones de } \\
\text { enfermedad del juez, del fiscal o } \\
\text { del imputado o su defensor; b) } \\
\text { por razones de fuerza mayor o } \\
\text { caso fortuito }\end{array}$ & $\begin{array}{l}\text { El } 75 \% \text {, no se suspenden sólo } \\
\text { por a) por razones de } \\
\text { enfermedad del juez, del fiscal o } \\
\text { del imputado o su defensor; b) } \\
\text { por razones de fuerza mayor o } \\
\text { caso fortuito }\end{array}$ & $\begin{array}{l}\text { El } 78 \% \text {, no se suspenden sólo } \\
\text { por a) por razones de } \\
\text { enfermedad del juez, del fiscal o } \\
\text { del imputado o su defensor; b) } \\
\text { por razones de fuerza mayor o } \\
\text { caso fortuito }\end{array}$ \\
\hline $\begin{array}{l}\text { El } 92 \% \text { refiere se estaría } \\
\text { afectando el principio de } \\
\text { inmediación }\end{array}$ & $\begin{array}{l}\text { El } 100 \% \text { refiere se estaría } \\
\text { afectando el principio de } \\
\text { inmediación }\end{array}$ & $\begin{array}{l}\text { El } 67 \% \text { refiere se estaría } \\
\text { afectando el principio de } \\
\text { inmediación }\end{array}$ \\
\hline $\begin{array}{l}\text { El } 87 \% \text { refiere no se cumple con } \\
\text { la presencia ininterrumpida de } \\
\text { los sujetos procesales }\end{array}$ & $\begin{array}{l}\text { El } 75 \% \text { refiere no se cumple con } \\
\text { la presencia ininterrumpida de } \\
\text { los sujetos procesales }\end{array}$ & $\begin{array}{l}\text { El } 78 \% \text { refiere no se cumple con } \\
\text { la presencia ininterrumpida de } \\
\text { los sujetos procesales }\end{array}$ \\
\hline $\begin{array}{l}\text { El } 88 \% \text { señalaron que, la } \\
\text { fragmentación del juicio oral } \\
\text { estaría afectando la calidad del } \\
\text { juzgamiento }\end{array}$ & $\begin{array}{l}\text { El } 75 \% \text { señalaron que, la } \\
\text { fragmentación del juicio oral } \\
\text { estaría afectando la calidad del } \\
\text { juzgamiento }\end{array}$ & $\begin{array}{l}\text { El } 89 \% \text { señalaron que, la } \\
\text { fragmentación del juicio oral } \\
\text { estaría afectando la calidad del } \\
\text { juzgamiento }\end{array}$ \\
\hline $\begin{array}{l}\text { El } 93 \% \text { señalaron que, se debe } \\
\text { modificar el artículo } 360^{\circ} \text { del } \\
\text { Código Procesal Penal }\end{array}$ & $\begin{array}{l}\text { El } 100 \% \text { señalaron que, se debe } \\
\text { modificar el artículo } 360^{\circ} \text { del } \\
\text { Código Procesal Penal }\end{array}$ & $\begin{array}{l}\text { El } 89 \% \text { señalaron que, se debe } \\
\text { modificar el artículo } 360^{\circ} \text { del } \\
\text { Código Procesal Penal }\end{array}$ \\
\hline
\end{tabular}

Resultados de la entrevista aplicada a los magistrados

1. ¿En su Despacho judicial la Audiencia de Juicio Oral se llevan a cabo de acuerdo a lo establecido en el artículo $360^{\circ}$ del Código Procesal Penal?

Se trata de cumplir lo establecido en la norma, pero por la excesiva carga procesal, inconcurrencia de los testigos se suspenden las audiencias de juicio oral.

2. ¿Considera usted que, en la Audiencia de Juicio Oral en el Juzgado Penal Colegiado de la Corte Superior de Justicia de Tacna, se estaría afectando el principio de concentración? Fundamente.

Sí, porque la audiencia de juicio oral es realizada en varias sesiones.

3. ¿Cuáles considera usted son las causas por las que se estaría afectando el principio de concentración en la Audiencia de Juicio Oral en el Juzgado Penal Colegiado de la Corte Superior de Justicia de Tacna?

Las causas por las que se estaría afectando el principio de concentración serían: la carga procesal, micro sesiones; y la inconcurrencia de testigos.

4. ¿Considera usted que, en la Audiencia de Juicio Oral en el Juzgado Penal Colegiado de la Corte Superior de Justicia de Tacna, se estaría afectando el principio de continuidad? Fundamente.

Sí, porque la audiencia de juicio oral se realiza en varias sesiones lo que afecta el principio de continuidad del juzgamiento.

5. ¿Cuáles considera usted son las causas por las que se estaría afectando el principio de continuidad en las Audiencias de Juicio Oral en el Juzgado Penal Colegiado de la Corte Superior de Justicia de Tacna?

Las causas por las que se estaría afectando el principio de continuidad en las Audiencias de Juicio Oral serían la fragmentación y dispersión del juicio oral en sesiones discontinuas.

Veritas et Scientia Vol. 7 (2) Julio - diciembre 2018. 911 
6. ¿Considera usted que, en las Audiencias de Juicio Oral en el Juzgado Penal Colegiado de la Corte Superior de Justicia de Tacna, se estaría afectando el principio de inmediación? Fundamente.

Sí, debido a la intermitencia de las sesiones, ya que se ha impuesto una práctica extralegal de "suspensión judicial" del juicio oral

7. ¿Cuáles considera usted son las causas por las que se estaría afectando el principio de continuidad en las Audiencias de Juicio Oral en el Juzgado Penal Colegiado de la Corte Superior de Justicia de Tacna?

Las causas por las que se estaría afectando el principio de continuidad en las Audiencias de Juicio Oral en el Juzgado Penal Colegiado de la Corte Superior de Justicia de Tacna serían la inconcurrencia de los órganos de prueba, la sobre abundancia de los testigos, entre otros.

8. ¿Considera usted que, en las Audiencias de Juicio Oral en el Juzgado Penal Colegiado de la Corte Superior de Justicia de Tacna, se estaría afectando el principio de inmediación? Fundamente.

En las Audiencias de Juicio Oral en el Juzgado Penal Colegiado de la Corte Superior de Justicia de Tacna, se estaría afectando el principio de inmediación debido a que no se permite captar la información en conjunto.

9. ¿Cuáles considera usted son las causas que están incidiendo en la fragmentación del juicio oral en el Juzgado Penal Colegiado de la Corte Superior de Justicia de Tacna? Fundamente.

En las Audiencias de Juicio Oral en el Juzgado Penal Colegiado de la Corte Superior de Justicia de Tacna, se estaría afectando el principio de inmediación debido a la excesiva carga procesal y la sobreabundancia de los testigos.

10. ¿Considera usted que la fragmentación del juicio oral estaría afectando la calidad del juzgamiento en el Juzgado Penal Colegiado de la Corte Superior de Justicia de Tacna? Fundamente.

Sí, porque impide conocer en una sola oportunidad todo lo actuado.

11.¿Cuáles considera usted serían las medidas y/o normas que se debería implementar para asegurar una eficiente calidad de juzgamiento en el juicio oral? Fundamente.

Se debe efectuar un escrito control de la admisibilidad de la prueba ofrecida, estableciendo su pertinencia, conducencia y utilidad. Las fechas de audiencia deben ser agendadas el especialista legal de causas tomando en cuenta el tipo de proceso.

\section{DISCUSIÓN}

La problemática de la fragmentación del juicio oral y la calidad de juzgamiento es de suma importancia, toda vez que la suspensión del juzgamiento no garantiza la justicia oportuna, afectando principios procesales tales como la concentración, inmediación y continuidad, que inciden en la calidad del juzgamiento. probablemente la fragmentación de la audiencia del juicio oral, afecte considerablemente la calidad del juzgamiento. Se ddeterminó que la fragmentación de la audiencia del juicio oral, afecta considerablemente la calidad del juzgamiento en el Juzgado Penal Colegiado de la Corte Superior de Justicia de Tacna-2016. Estos resultados son congruentes con el estudio de: López, C. (2012) donde señala que la

Veritas et Scientia Vol. 7 (2) Julio - diciembre 2018. 912 
prolongación excesiva de la audiencia de juicio oral por sucesivas suspensiones de la audiencia, configura causal de nulidad por violación de la garantía fundamental al Debido Proceso, por desconocimiento de los principios de concentración e inmediación. Asimismo, la Jurisprudencia en Huaura Jurisprudencia en Huaura Sala Penal de Apelaciones Sala Penal de Apelaciones. EXPEDIENTE 2007--00307-14--1308--SSPP--PPEE-1 señala sobre el desarrollo del juicio oral de Primera Instancia que el Juez para sustentar una condena contra una persona debe tener en cuenta -siempre- lo dispuesto en el artículo II. 1 del Título Preliminar del CPP, que establece que, para dicho fin, se requiere de una suficiente actividad probatoria de cargo, obtenida y actuada con las debidas garantías procesales. Siendo que, los principios y garantías procesales se encuentran expresamente enumerados en el artículo 356.1 del citado código, donde se consigna especialmente la oralidad, la publicidad, la inmediación y la contradicción de la actuación probatoria.

Asimismo, los diferentes tipos de procesos en juicio oral estarían afectando considerablemente al principio de concentración. Estos resultados son congruentes con el estudio de: Cajas, A. (2009) que señala: "El juicio es considerado como un filtro de información por sus principios básicos, los cuales son: oralidad, celeridad, publicidad, inmediación, contradicción, continuidad, dispositivo, simplificación, eficacia". Para que el juicio cumpla su rol es necesario que se depuren los rezagos inquisitivos que aún contiene.

Se evaluó la variable dependiente "continuidad" a través de sus indicadores: porcentaje de juicios orales discontinuos, número de sesiones por juicio oral, cumplimiento de causales legales de suspensión, determinándose que la suspensión del juicio oral estaría afectando considerablemente el principio de continuidad en el Juzgado Penal Colegiado de la Corte Superior de Justicia de Tacna-2016. Respecto a la variable dependiente "inmediación" a través de sus indicadores: presencia ininterrumpida de los sujetos procesales, tiempo aproximado por sesión y la interrelación directa entre los jueces y la prueba, se determinó que la instalación simultánea de audiencias estaría afectando considerablemente el principio de inmediación. Estos resultados tienen relación con los resultados del estudio de: Murillo, I. (2010). Juicios orales en materia penal para el estado de baja californias, de la Universidad de Autónoma de Baja California Sur; señala que: Los juicios orales tendrán las mismas etapas de un juicio escrito, solo que en un menor número de audiencias y de forma oral, esto se hace con el objetivo de reducir tiempo y dinero.

El Poder Judicial debe elevar una propuesta legislativa al Congreso con la modificatoria del artículo $360^{\circ}$ del Código Procesal Penal, en el cual debe establecerse que, entre sesiones, o durante el plazo de suspensión, no deben realizarse otros juicios, a fin garantizar la calidad de juzgamiento, salvo que se traten de procesos con prisión preventiva y haya amenaza de excarcelación.

\section{REFERENCIAS BIBLIOGRÁFICAS}

Alsina, R.(1956). Tratado teórico-práctico de Derecho Procesal Civil y Comercial, 2a ed., T. 1, Parte General.Buenos Aires: Ediar, p. 136.

Ccasa, G. (2016). Necesidad de la aplicación de la cesura de juicio oral como mecanismo procesal para optimizar los derechos constitucionales en el proceso penal en el Perú, durante los años 2013-2014, Universidad Nacional de San Agustín.

Cajas, A. (2009). El juicio oral como garantía del debido proceso en materia penal en el Ecuador, de la Universidad Técnica Particular de Loja.

Fernández, I. (2010). El Juicio Oral y Público como etapa fundamental del proceso, de la Universidad José Antonio Páez

Frank, J. (1986). Sistema Acusatorio Criminal y Juicio Oral. Buenos Aires: Lerner, p. 25.

Veritas et Scientia Vol. 7 (2) Julio - diciembre 2018. 913 
Levene, R. (1993.). Manual de Derecho Procesal Penal, 2a ed., T. 1, Buenos Aires: De palma, p. 105.

López, C. (2012). Nulidad por violación a normas rectoras de inmediación y concentración de la prueba en el sistema penal acusatorio Colombiano, de la Universidad de Medellín en convenio con la Fundación Universitaria Católica del Norte.

Maier, J.(2004). La Oralidad en el proceso penal. Publicidad y oralidad en el juicio penal.

Mejía, G. (2001). Principios orientadores del juicio oral y público en el proceso penal Venezolano, de la Universidad Católica Andrés Bello; Maracaibo.

Murillo, I. (2010). Juicios orales en materia penal para el estado de Baja California, de la Universidad de Autónoma de Baja California Sur.

Ossorio, M., (2007) Diccionario de Ciencias Jurídicas Políticas y Sociales, Publicidad de los juicios, 1 a edición electrónica, Guatemala, p. 795.

Osorio, O, \& Sierra, L. (2015). Ventajas y desventajas de la oralidad en la justicia colombiana. Caso Manizales, de la Universidad de Manizales.

Ramírez, J. (2011). Políticas de Oralidad implementadas por el Poder Judicial del período 2006 al 2008 en el Proceso Penal Costarricense, de la Universidad de Costa Rica.

San Martín, C. (2005). Introducción general al estudio del Nuevo Código Procesal Penal». En: El Nuevo Proceso Penal. Estudios Fundamentales. Palestra, Lima.

Torres, A. (2013). La importancia del lenguaje no verbal en los Juicios orales en México, de la Universidad de Autónoma de Baja California Sur.

Veritas et Scientia Vol. 7 (2) Julio - diciembre 2018. 914 